\title{
Gênero, trabalho e ação política \\ no setor agrícola alagoano.*
}

Belmira Magalhães ${ }^{1}$

Geice Silva ${ }^{2}$

Felipe Thadeu Salles Motta ${ }^{3}$

Resumo: Este artigo, a partir da fala de mulheres que participam da atividade agrícola, em Alagoas, tanto como trabalhadoras do setor como companheiras dos trabalhadores, apresenta dois enfoques principais que têm as relações de classe como determinante e o machismo como pontecializador da exploração do trabalhador. Enfatizamos o trabalho doméstico não remunerado, as consequências dessa atividade para a conscientização da mulher e, finalmente, a naturalização da descriminação feminina que se constrói, a partir da ênfase nas afetividades familiares.

Palavras-chave: Relações de produção e relações de gênero, trabalho doméstico não remunerado, exploração e afetividade.

Abstract: This article is based on the accounts of women who are engaged in the agricultural activity in Alagoas (Brazil), as workers or as companions of workers. It presents the three main approaches that are determined by class relations and machismo, which potentiates the exploitation of the worker. We emphasize the unpaid domestic work, its consequences for the consciousness of women and, lastly, the naturalization of the discrimination against women which is formed through the emphasis in familial affections.

Keywords: Relations of production and gender relations; unpaid domestic work; exploitation and affection.

\footnotetext{
${ }^{1}$ Professora/pesquisadora do Instituto de Ciências Sociais e da Faculdade de Letras, da UFAL. Coordenadora do Núcleo de Estudo e Pesquisa sobre a Condição Feminina, do ICS e dos grupos de pesquisa Gênero e Emancipação Humana e Análise do discurso, do CNPq.

${ }^{2}$ Mestra em Sociologia pelo Programa de Pós-Graduação em Sociologia, do Instituto de Ciências Sociais, da UFAL.

${ }^{3}$ Bacharel em Ciências Sociais, UFAL, e-mail: salesmft@gmail.com.
}

Latitude, vol. 5, no 1 , pp. 85-111, 2011

DOI: https://doi.org/10.28998/2179-5428.20110104 
Gênero, trabalho e ação política no setor agrícola alagoano.

\section{INTRODUÇÃO}

Neste artigo serão apresentadas as análises desenvolvidas das pesquisas financiadas pelo Programa Institucional de Bolsas de Iniciação Científica (PIBIC/CNPq/PROPEP-UFAL) pelo/as integrantes do Grupo Gênero e Emancipação Humana, cadastrado no Diretório de Grupos de Pesquisa do Conselho Nacional de Desenvolvimento Científico e Tecnológico (CNPq), desde 2008. No segundo semestre desse mesmo ano, o grupo iniciou uma parceria com outro grupo, também do $\mathrm{CNPq}$, coordenado pela Profa. Dra. Alice Anabuki Plancherel, denominado Trabalho e Capitalismo Contemporâneo, com o propósito de estudarmos a atividade sucroalcooleira de Alagoas na contemporaneidade. Seguindo essa trajetória científica, focamos as pesquisas na participação da mulher na referida atividade, tanto como trabalhadora propriamente dita, quanto pela participação como reprodutora da força de trabalho, isto é, como esposa dos trabalhadores e mãe dos futuros trabalhadores.

O enfoque das três abordagens realizadas dar-se-á com o objetivo de mostrar os caminhos seguidos e as conclusões obtidas. Analisamos os discursos de trabalhadoras do setor sucroalcooleiro, assim como das companheiras - esposas de trabalhadores desse setor. Num segundo momento, investigamos a participação das trabalhadoras do Movimento dos Trabalhadores Sem Terra (MST) acampamento São José, Atalaia-AL - nas atividades do campo, na rotina doméstica e no espaço político.

A abordagem metodológica aliou análises qualitativas e quantitativas, por possuir caráter teórico-empírico. Os dados empíricos formaram o perfil das trabalhadoras. Foram realizadas entrevistas de caráter semi-estruturado, seguindo um roteiro contendo perguntas abertas e fechadas, inicialmente com questões fechadas visando obter informações de natureza quantitativa e qualitativa de maior precisão - informações sociodemográficas, tais como sexo, idade, local de nascimento, tempo de serviço, escolaridade etc.

Após o término das transcrições de grande parte das entrevistas, os pesquisadores analisaram três aspectos no discurso das mulheres: a) Quais eram as atividades domésticas desenvolvidas em seus lares, quem as desenvolvia e qual o tempo gasto (horas e minutos) -quantificação das horas de trabalho doméstico; b) enunciados que envolvessem a questão de gênero (machismo, papel da mulher na família etc.); c) discursos sobre o Movimento dos Trabalhadores Rurais Sem Terra (MST) que indicavam a compreensão das entrevistadas sobre esse movimento social, quais as mudanças em seus cotidianos depois que ingressaram em movimentos de luta pela terra etc. 
A adoção das categorias da Análise do Discurso (AD) de linha francesa foi relevante para desvendar o que fica silenciado pela materialidade linguística do discurso. As três categorias principais são o dito, o não-dito e o silenciado. $\mathrm{O}$ dito representa a fala em si, isto é, dizer que a participação das mulheres no movimento é importante para a construção da igualdade de gênero, por exemplo, expressa a frase em si, não o que se encontra subjacente a esse discurso. Já o não-dito diz respeito à interpretação do discurso em questão, em que se analisa o discurso a partir de suas condições de produção, isto é, uma determinada materialidade no interior da fala. O silenciado está ligado à dimensão apenas indicada na materialidade do discurso, é o que fica silenciado e que revela as contradições sociais existentes no interior da sociedade em que o discurso foi produzido.

\subsection{Machismo: condição intrínseca ao capitalismo?}

A inferiorização social das mulheres não surgiu com o capitalismo, mas subsidia a intensa prática de exploração das trabalhadoras a fim de desvalorizar a sua força de trabalho. Dessa forma, a mais-valia extraída dessa população é maior, assim como é maior a mais-valia extraída de outras camadas vulneráveis socialmente, como imigrantes, negros e homossexuais.

Diante da lógica intrínseca ao capitalismo, não há diferenças entre sexo, cor, etnia, opção sexual para a exploração da força de trabalho humano. Todos são livres, juridicamente, para vender a sua força de trabalho. Condição conquistada pela emancipação política na Revolução Burguesa. Esse fato levou alguns autores marxistas, como Perry Anderson e Ellen Wood (1984, p. 105) apud Gonçalves (2011), a afirmar que "a lógica do lucro é indiferente à diversidade sexual" e que a tendência do capital é homogeneizar as identidades.

Para Dedecca (2004), porém, o papel cumprido na reprodução social no âmbito das famílias-domicílios articula-se com o tempo econômico para o processo de acumulação capitalista, ou seja, embora as opressões não tenham origem no capitalismo, servem de base para a reprodução familiar/social deste sistema. Por isso, para o autor supracitado, o tempo nas análises sociais deveria ser considerado não apenas como tempo para reprodução econômica - aquele que é destinado ao trabalho remunerado e o gasto com deslocamento para sua realização -, como também o tempo para reprodução familiar/social - que incorpora as atividades de organização domiciliar, de lazer e de sono.

Essa divisão revela que o serviço doméstico, embora com uma importante função social, não é trabalho produtivo porque ele não interfere diretamente na produção da mais-valia. Ele é um serviço integrado às condições de reprodução do capital, pois possibilita as condições de manutenção da força de trabalho.

As sociedades de classe constituíram uma divisão sexual do trabalho que destinou às mulheres ao âmbito privado, controlando sua força de trabalho e sua 
Gênero, trabalho e ação política no setor agrícola alagoano.

sexualidade para garantir filhos legítimos, "dignos do direito à herança", ao mesmo tempo, a produção e reprodução da força de trabalho para desenvolver seres vivos aptos para o trabalho e seres históricos aptos para determinado modo de produção (MAGALHÃES, 1997).

Na sociedade contemporânea, o ingresso das mulheres em atividades de trabalho fora do âmbito doméstico perpassa todas as contradições da sociedade e, em particular, as de classe e de gênero.

Desse modo, os dados encontrados na pesquisa ajudam a refletir sobre quão difícil é o cotidiano das trabalhadoras em Alagoas e no país. Reafirma-se que o aumento da participação das mulheres no mercado de trabalho e o crescimento dos níveis de escolaridade acompanham as desigualdades resultantes da relação dominante/dominado que marcam profundamente as relações de gênero, as quais implicam perdas não só para as mulheres mas, fundamentalmente, para o conjunto da classe da mulher trabalhadora.

Agregam-se a essas constatações, o processo de invisibilidade do trabalho doméstico no mundo do trabalho, devido a não computação desses dados pelos institutos de pesquisa de dados oficiais (tais como IBGE, PNAD), além do que, fato ainda mais preocupante, os membros das próprias famílias não reconhecem o valor do trabalho realizado dentro do lar, pois só se referem ao trabalho em relação às mulheres quando é exercido fora do âmbito doméstico. Esse tipo de ocorrência, além de naturalizar o trabalho da mulher, considerada como "dona de casa", acarreta um ganho enorme para os empregadores que contam com o cuidado diário proporcionado aos trabalhadores através da alimentação, limpeza do espaço de repouso e das roupas realizado pela mulher e cria uma desvalorização do trabalho feminino, como veremos adiante.

\section{TRABALHO E MULHER: A SITUAÇÃO NO CONTEXTO ATUAL}

O índice das mulheres "economicamente ativas" cresce no Brasil, ocupando novos lugares, mas mantendo lugares muito antigos. Nos últimos anos houve um aumento expressivo da chefia feminina na atual estrutura familiar: passou de $0,8 \%$ em 1992 para 9,4\% em 2009 (CEPIA; ONU MULHERES, 2011, p. 145). No entanto, em 2009, constatou-se que $90 \%$ das mulheres brasileiras com 16 anos ou mais de idade afirmaram realizar tarefas domésticas, comparados a 50\% dos homens. Em média, as mulheres ocupam 22 horas semanais com a atividade doméstica não remunerada (IPEA, oㅜ 149, 2012, p. 04), como mostra o gráfico abaixo: 

trabalho. Brasil, 2009

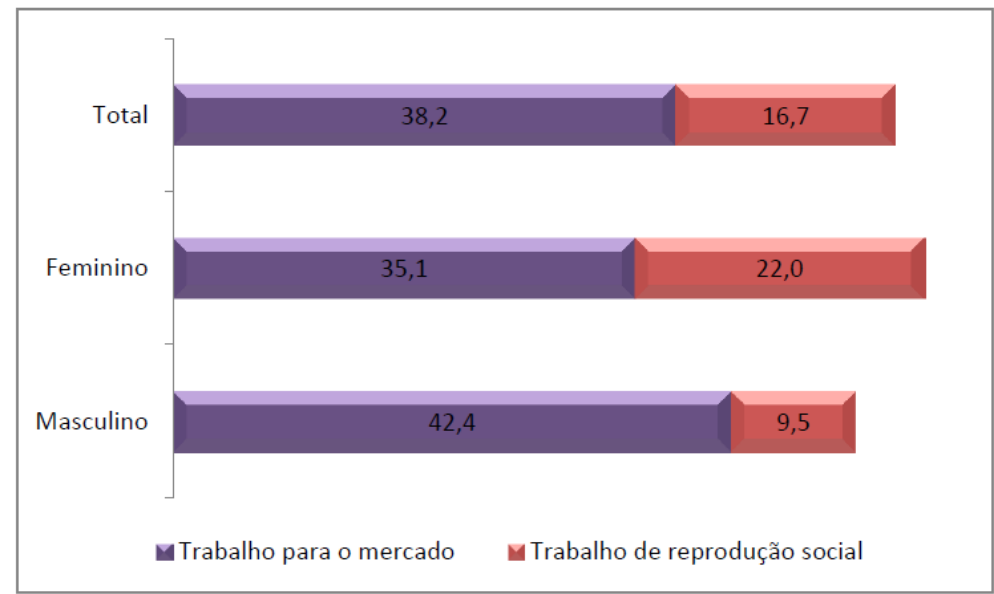

Fonte: PNAD/IBGE. Elaboração: IPEA

Obs.: A carga global de trabalho representa o somatório da jornada média semanal na ocupação principal com o tempo médio semanal dedicado aos afazeres domésticos. População ocupada com 16 anos ou mais de idade e que se dedica a afazeres domésticos.

Essa desigualdade não se modifica se as mulheres são mais ocupadas que os homens nos serviços remunerados (elas ainda gastam 10 horas a mais por semana com essas tarefas do que os homens na posição oposta, ou seja, desocupados), se a renda for maior que a de seus companheiros ou se são chefes de família. A obrigação é sempre delas e cabe ao homem uma maior ou menor "ajuda".

Essa condição é evidenciada a partir dos discursos, como podemos constatar nestas duas materialidades, retiradas de entrevistas feitas com duas acampadas do MST em Alagoas, em 2011:

Entrevistador - [perguntando se seu filho a ajuda voluntariamente nas tarefas domésticas] Ele, precisa mandar muito?

Entrevistada F.- Rapaz, quando ele tá só... quando eu saio, ele faz tudo. Agora, quando ele tá mais eu, ele é meio...

Entrevistador - Como é tua atividade aqui no acampamento? É só ficar em casa, vai pra roça de vez em quando...

Entrevistada Z. - É assim, ficar em casa e... fazer serviço doméstico, cuidar dos animais, já que meu marido não pode porque vai pra roça, aí eu quem "toma de conta", da casa e dos animais, assim... 


\section{Gênero, trabalho e ação política no setor agrícola alagoano.}

Além da diferença na quantidade de horas despendidas, várias pesquisas têm discutido sobre a especificidade das tarefas executadas no trabalho para a reprodução social (HIRATA, 2002). As atividades centrais são aquelas fundamentalmente ligadas ao cuidado (acompanhamento dos filhos, preparação de alimentos, higienização dos ambientes etc.), as quais em larga medida não têm corresponsabilidade social no interior das famílias, pois estão concentradas nos cuidados femininos.

Como vem sendo discutido há décadas, a forma de realização da discriminação feminina através da ideologia patriarcal na praxis cotidiana está em naturalizar a função da maternidade. Ao transformar as mulheres, prioritariamente, em mães, cria-se um processo metonímico de inculcação ideológico-inconsciente, que resulta em todos os seres sociais assimilarem a concepção do papel social das mulheres ser essencialmente mães, esposas, enfim "rainhas do lar" (MAGALHÃES, 2005).

Dados de uma pesquisa anterior realizada pelo grupo Gênero e Emancipação Humana (UFAL/CNPq), no período de 2005 a 2008, tendo como alvo as estudantes da UFAL, apontaram que as inúmeras cobranças de âmbito matrimonial revelam que o aumento da individuação feminina (aqui representado pelo nível de escolaridade e ingresso no mercado de trabalho) convive com sua subjugação na família. Quando questionamos as estudantes sobre quais seus principais problemas enfrentados na família, enquanto mulheres, as reclamações das estudantes circularam sempre em torno da temática do tempo dedicado às tarefas domésticas:

Entrevistada A: "Fico com todas as tarefas domésticas, além de trabalhar e ainda estudar. Horrível."

Entrevistada B: "Sempre o trabalho doméstico é da mulher."

Entrevistada C: "Falta de tempo para todas as atividades domésticas e com o filho"

(Fonte: Pesquisa A mulher na universidade, no trabalho e na família. PIBIC/CNPq, 2005-2008)

Assim, mesmo que a mulher ocupe atividades de estudo e trabalho há uma cobrança social baseada no fato de que seu lugar primordial é como esposa e mãe, uma contradição em vista do processo contemporâneo do crescimento da individuação.

O capitalismo tem a característica de não ir até as últimas consequências em sua "economia de tempo" para a produção social, inédita na história até o advento 
da Revolução Industrial (1780), pois o avanço do desenvolvimento tecnológico não representa uma reversão do tempo para a reprodução social, tampouco para o tempo livre. No que diz respeito a diminuição e regulação da jornada de trabalho, as históricas lutas sociais das trabalhadoras e dos trabalhadores do início do século XX cumpriram o papel de colocar em pauta para a sociedade o problema do tempo social no modo capitalista de produção.

Existem eletrodomésticos que facilitam o serviço dentro de casa, mas, além da maioria da população não ter poder aquisitivo para comprá-los, as mulheres que os possuem podem não estar em um ambiente propício que as estimulem a ter interesses exteriores àqueles que se apresentam imediatamente, limitando-se, assim, à vida privada da família. Ademais, com a flexibilização do trabalho a partir da década de 1980, os trabalhadores não têm mais tempo livre. Aumentou o tempo de trabalho social (o tempo dedicado à reprodução familiar) ao mesmo tempo em que aumentou a desigualdade social.

Outro impeditivo para a participação da mulher na produção e nas decisões sociais é a maternidade involuntária. Embora existam creches, acesso a contraceptivos e o direito ao aborto em alguns países, estes elementos sempre se mostram limitados para uma grande esfera da população, contribuindo com a ideologia da primazia feminina sob o papel reprodutivo na sociedade. O déficit destes serviços no Brasil é gigantesco, e ainda maior em Alagoas: de acordo com dados do IBGE (2010), 92\% das crianças no Estado não têm acesso a creches.

Sendo assim, a explicação marxista da opressão não se apoia em supostas justificativas biológicas, como é feito por diversos teóricos que defendem a inferioridade ou a superioridade da mulher em relação ao homem. Teses baseadas nas características "naturais" foram muitas vezes, inclusive, usadas para defender a possibilidade de um capitalismo "mais humano", que seria aquele administrado por mulheres. A história desmentiu esta concepção com diversos exemplos, como Margaret Tatcher, a precursora das medidas neoliberais que pioraram a vida dos trabalhadores ingleses desde os anos 1970.

O que o marxismo defende é que os seres humanos são determinados pelas circunstâncias materiais. Em O 18 Brumário de Luís Bonaparte, Marx (2008, p. 207) discute que "[o]s homens fazem a sua própria história, mas não a fazem segundo a sua livre vontade, em circunstâncias escolhidas por eles próprios, mas nas circunstâncias imediatamente encontradas, dadas e transmitidas pelo passado".

Se a realidade mostra alguma semelhança entre as mulheres em relação às formas de agir, isto se dá devido ao modo como elas são educadas e levadas a acreditar quem são. $\mathrm{O}$ mesmo se diz dos homens. Se os homens são supostamente mais agressivos, foram as circunstâncias materiais que os fizeram dessa forma. A essência humana é histórica. Prova disto é que não se confirma que em todas as sociedades a mulher foi vista como socialmente inferior, tampouco em todas as 


\section{Gênero, trabalho e ação política no setor agrícola alagoano.}

sociedades o papel atribuído a cada gênero foi o mesmo ${ }^{4}$. Como dito por Orr (2011), a socialização é moldada pela forma como a sociedade está estruturada, e a família tem um papel fundamental na reprodução da ideologia dominante.

\section{A CONSCIÊNCIA POLÍTICA}

A temática do movimento da consciência de classe é abordada como um processo no qual se expressam várias particularidades que se complementam. Desse modo, as três "etapas" principais a serem discutidas podem conter elementos em comum, ao mesmo tempo, representa um determinado salto (IASI, 2006). Em contrapartida, costuma-se falar em "processo de consciência" e não em "consciência" como algo apriorístico, visto que isso implicaria na existência de uma dimensão oposta, que é a "não-consciência", consequentemente, dando espaço a uma análise mecânica das relações sociais e históricas.

Assim, a consciência, inicialmente, constrói uma representação mental subjetiva de uma realidade que é externa, isto é, está associada a um conjunto de relações sociais que são cristalizadas e passam a se expressar de forma naturalizada, como se fossem distintas do movimento da história e existissem para todo o sempre.

Conforme os dados das nossas pesquisas, os militantes do Acampamento São José reuniam-se semanalmente para decidir, em discussões, os rumos políticos que seriam traçados pelos acampados. As reuniões eram abertas à participação, em tese, de quem tivesse interesse em estar nos espaços. As respostas de cunho machista às indagações que mais escutávamos estavam ligadas à participação das mulheres casadas nessas reuniões:

Entrevistador - Já aconteceu de o marido de alguma mulher colocar dificuldade pra ela participar?

Entrevistada - Já, aconteceu. Sempre acontece.

[...]

Entrevistador - Mas, como é essa questão de sempre acontecer dos maridos colocarem dificuldade para as esposas irem?

Entrevistada - É... porque eles trabalham no campo... aí, eles bota elas pra ir. Aí, eles trabalha no campo, às vezes, quando tem reunião "pera" noite, que ele chega muito cansado... que já chega 5:30h, 6:30h da noite... a reunião vai ser 8:00h, 7:00h... aí, eles não têm...

\footnotetext{
${ }^{4}$ Encontramos alguns exemplos, como o de sociedades primitivas na Nova Guiné, no livro
} Mulheres: o gênero nos une, a classe nos divide (2008), de Cecília Toledo. 
não têm muito tempo. Aí, quem vem é elas (entrevista: acampamento-1).

Pode-se perceber, em discursos como esse, que a participação feminina ocupa um segundo plano, sendo visto - muitas vezes - como um paliativo à ausência e opinião do homem nas reuniões.

As rotinas domésticas das entrevistadas casadas estavam sujeitas aos trabalhos e atividades de seus maridos, fossem na própria roça do acampamento, ou em alguma usina sucroalcooleira. Transcrevemos um desses exemplos:

Entrevistador - E quando o marido da senhora tá trabalhando? Como é que é?

Entrevistada - Aí, quando ele, assim, ele vai trabalhar, ele sai de 3:00h da manhã pra ir trabalhar. Aí, quando ele chega, as coisas já tá, não todas feitas, né? Aí, boto água, trago água pra casa, pra eles tomar banho, boto água em casa... e quando, assim, quando ele chega, às vezes ele arreclama que só, porque eu não tenho feito nada e porque o fogo tá apagado [...]. "Óia, como aqui fica dentro de casa, duas mulé dentro de casa e não faz nada dentro de casa!?" [reproduzindo a reclamação do marido] (acampamento-8).

Percebemos aí a questão da naturalização da divisão sexual do trabalho, e como efeito, recai sobre as mulheres a responsabilidade pelo espaço doméstico, enquanto ao homem cabe o papel de mantenedor da casa. Atrelado a isso, encontramos também a naturalização da maternidade e a responsabilidade pela sociabilidade das crianças, atividade atribuída sempre à mãe. Ainda hoje, a maternidade e a gravidez são utilizadas como fortes argumentos que limitam a participação da mulher no mercado de trabalho, subjulgando-a a um lugar de inferioridade em relação ao homem, apoiados em uma naturalização de condições criadas socialmente. Essas relações iniciais, ao serem naturalizadas, perdem seu caráter histórico e são internalizadas pelos indivíduos em seu processo de formação.

Mészáros (1993, p. 79), no capítulo “Consciência de Classe Necessária e Consciência de Classe Contingente", presente no livro Filosofia, Ideologia e Ciência Social, explica que a consciência tem uma estrutura própria com autonomia relativa. As condições materiais sempre irão constituir a pré-condição para que a efetivação da vida humana, assim, "as forças produtivas tiveram de alcançar um certo grau de desenvolvimento antes que se tornasse possível separar 'objetivação' de 'alienação'". Porém, o papel da consciência se torna cada vez mais forte com o 


\section{Gênero, trabalho e ação política no setor agrícola alagoano.}

decorrer da história e do desenvolvimento das forças produtivas, fazendo com que, ao mesmo tempo em que é determinada, também determine a vida social. Portanto, não se pode entender esta categoria de forma isolada ou mecanicista, nem no que concerne ao posicionamento de que a consciência é uma necessária determinação direta da situação econômica, tampouco que ela está apartada das condições materiais em um determinado momento histórico-social.

Os capitalistas e os operários - exploradores e explorados - são as duas classes fundamentais do capitalismo. Sem elas seria impossível manter a exploração da mais-valia. As duas, porém, têm relações bastante distintas com o modo de produção e, portanto, produzem ideologias distintas. Os capitalistas (a burguesia), por sua posição privilegiada, querem manter a "ordem" das coisas. Marx define o capitalista nos Manuscritos Econômico-Filosóficos como aquele que só tem interesse no lucro retirado do emprego da força de trabalho. Não lhe interessa o ponto de vista da sobrevivência do trabalhador nem a utilidade que a riqueza produzida tem para a sociedade.

Enquanto o proletário é obrigado a extinguir-se como condição de sua sobrevivência e, consequentemente, extinguir aquilo que o transforma em proletariado, ou seja, a propriedade privada nos moldes capitalistas. Neste modo de produção, "o trabalhador existe para satisfazer as necessidades de autoexpansão dos valores existentes, ao invés da riqueza material existir para satisfazer as necessidades de desenvolvimento do trabalhador" (MÉSZÁROS, 1993, p. 91). O proletariado resume, assim, toda a miséria a que a humanidade tem de se submeter no sistema de produção de mercadorias, tanto no terreno material quanto espiritual. Alguns autores colocam que esta diferenciação está ultrapassada e que as classes sociais, de formas diferentes, têm se fundido umas com as outras. Um exemplo desse processo seria a massificação dos meios de produção. O posicionamento de Meszáros em relação a isso é bastante claro: enquanto existem alguns fenômenos que apontariam uma suposta "convergência" entre a classe exploradora e explorada, perduram as diferenças estruturais baseadas na subordinação real do trabalho ao capital.

Os integrantes do MST, embora vivendo uma situação dúbia de assentados e trabalhadores eventuais em usinas compõem o conjunto da população desprovida dos meios de produção de bens necessários à reprodução da vida humana, sofrem as consequências que a exploração de classe produz entre interesses particulares e coletivos que interferem diretamente no nível de conscientização política.

Ao contrário dos indivíduos da classe dominante, para os quais o interesse de classe não se choca com os interesses particulares, os interesses "a curto prazo" dos indivíduos pertencentes à classe dominada, muitas vezes, chocam-se com os interesses de mudança estrutural da sociedade. Porém, nem toda ação individual por melhoria social enfraquece a consciência de classe, assim como nem toda ação em grupo a fortalece. É preciso levar em conta os objetivos envolvidos. 
É importante pontuarmos que os conflitos entre indivíduos da mesma classe podem originar subgrupos, subclasses, estamentos etc. Os modos distintos de envolvimento podem gerar o indivíduo isolado que age pelo autointeresse imediato (e que acaba por universalizar a sua individualidade); o grupo parcial com integrantes unidos pela manutenção de privilégios; o grupo hegemônico conservador que pretende preservar a estrutura social atual; o grupo periférico que se opõe à polarização de classes; e o grupo hegemônico dinâmico que consegue alcançar o ser humano universal concreto.

\subsection{Trabalho doméstico e consciência}

Pelos elementos expostos anteriormente, o trabalho doméstico e a vida familiar representam uma importante esfera na construção da subjetividade das mulheres e, consequentemente, em sua tomada de consciência como sujeitos produtores de sua própria história, pois, como dito por Marx em A Sagrada Família apud Mészáros (1993), "a história não é nada a não ser a atividade do homem que persegue seus objetivos". Sendo um serviço não remunerado e praticado na esfera privada, longe das decisões que dizem respeito à coletividade social, muitas vezes as mulheres se sentem como impotentes e dependentes de forças exteriores. É o que nos mostra a seguinte materialidade:

Entrevistador - Quando o marido da senhora tá em casa, quando ele não tá na usina, como é que é... em casa?

Entrevistada D. - É... em casa ele sai, arruma um biquinho num canto, biquinho em outro. É assim, aí, vai levando a vida, né, como Deus quer, né? Pessoa tem que viver como Deus quer, mas não, assim, fazendo coisa errada, né? A pessoa tem que viver, levar a vida no... do jeito que Deus mandar, né? Porque... tem marido assim, né, que se mete cachaça, deixa a mulé passar fome, né, G. [falando com uma mulher que estava tinha se sentado próximo ao local da entrevista e podia ouvi-la]? Deixa a pessoa passar decepção, aí vê a pessoa procurando um punhado de farinha mais os fio e não encontra. E depois, que minha fia, graças a Deus, tá recebendo esse benefício, graças a Deus, na minha casa num tá faltando mais nada. Porque, o que eu procurar dentro de casa, eu encontro: minha comida, num nada, graças a Deus na minha casa num falta mais não... 


\section{Gênero, trabalho e ação política no setor agrícola alagoano.}

Nota-se que a entrevistada D. apresenta uma posição de passividade em relação às questões fundamentais em sua vida, seja para transferir o lugar de ação para a figura divina, o marido ou a "boa vontade" do Estado.

A condição de quem manterá a ordem do lar baseia-se, em nossa sociedade, no fato de que apenas as mulheres podem gestar os filhos. O capital lucra menos com mulheres que precisam de licença-maternidade. Para compensar essa perda, a força de trabalho feminina passa a custar menos e as empresas se negam a construir creches, lavanderias e restaurantes públicos, que aliviariam sobremaneira as responsabilidades das mulheres. Como forma de legitimar a situação, essas medidas são justificadas pela ideologia machista, que também a identifica como um problema entre indivíduos, que não diz respeito à coletividade:

Entrevistada B. [sobre brigas no acampamento] Era só entre os homens. Era... aí, então... era, [...] brigava, assim, mulher com marido, pra lá. Mas a gente deixava pra lá.

Faz-se necessário afirmar que a realidade das mulheres do campo é ainda mais difícil de ser modificada do que a das mulheres urbanas, por conta da falta de investimentos governamentais destinados aos trabalhadores rurais, pela falta de oferta de empregos às mulheres do campo etc. Porém, as materialidades discursivas coletadas nesta pesquisa são de mulheres organizadas em um importante movimento social, portanto, algumas mudanças poderiam ter sido encontradas. A dificuldade em combater o machismo é gigantesca, especialmente no estado de Alagoas, onde, dos/as trabalhadores/as que não possuem carteira assinada, $72 \%$ são mulheres; o número de homicídios contra mulheres é o maior do Nordeste; e $70 \%$ dos assassinatos de mulheres são originados por violência doméstica. $\mathrm{O}$ fato de termos encontrado esta situação de machismo em um espaço de movimento social mostra o quanto está inserida no inconsciente dos sujeitos e o quanto ela é útil para explicar a situação de desigualdade que persiste na sociedade.

Nas entrevistas, mostrou-se que o serviço doméstico é destinado à mulher baseando-se também no princípio de que o homem é mais forte para trabalhar na roça e fazer serviços "pesados".

Entrevistador - Qual foi a participação das mulheres que vocês conseguiram, foi importante...

Entrevistada H. - Foi tudo junto, em conjunto, homem misturado com mulheres, tudo.

Entrevistador - Mas e na organização do acampamento depois? 
Entrevistada H. - Na organização separou depois: mulher pra cozinha e homens pra trabalhar nos serviço pesado.

Entrevistador - Montar barraca...

Entrevistada H. - Montar barraca, procurar lenha pra fazer as comidas e a mulher é mais assim...

No trecho seguinte, o marido não identifica como trabalho o fato da entrevistada preparar toda a comida que ele levará ao trabalho e acordar de madrugada para ajudá-lo a se arrumar. Apesar da entrevistada D. apresentar um imenso avanço em perceber que se esforça no serviço doméstico a ponto de defendê-lo como trabalho, é inquestionável o fato do serviço doméstico ser, em primeiro lugar, obrigação da mulher:

Entrevistada D. - [a entrevistada explica que, muitas vezes, prepara a comida no dia anterior para o marido levar pela manhã, quando vai trabalhar] Aí, ele leva... aí, ele arreclama, ele diz: 'mas, rapaz, tanto que eu trabalho, e essa mulher não me ajuda!' Aí, eu digo: 'ôxe, e eu também!? Você me ajuda a fazer as coisa de dentro de casa?' Ele diz: 'não, o direito da mulher é fazer as coisa', eu digo também: 'o direito do homem é ajudar a mulher'.

Quanto ao papel de subordinação da mulher em relação ao homem nas atividades coletivas, é possível encontrar o tema nos trechos a seguir. De entrevista feita à B, sobre as dificuldades "postas" pelos maridos para a participação das mulheres nas reuniões políticas do acampamento, notamos a existência de autoridade do marido:

Entrevistada B. - Sempre acontece. Pra elas acompanhar...?

Entrevistador - Sim, pra ir pra uma reunião...

Entrevistada B. - Vai: elas vão.

Entrevistador - Então, mas eles incentivam ou acontece de algum marido não querer que a mulher fosse?

Entrevistada B. - Não.

Entrevistador - Não?

Entrevistada B. - Não aconteceu não. Até aqui, não.

Entrevistador - Certo...

Entrevistada B. - Até aqui, não aconteceu de nenhum... todos ele manda.. elas... 


\section{Gênero, trabalho e ação política no setor agrícola alagoano.}

A pergunta foi se alguns maridos colocam empecilhos para a participação de suas esposas ou filhas nas atividades do movimento. A entrevistada B. diz que as mulheres vão, mas usa expressões como "acompanhar" e "mandar", outra entrevistada usa a expressão "alguns maridos acham que pode", ou seja, a participação das mulheres nos espaços coletivos é secundária e feita sob o mando do marido. Elas não enfatizam a vontade das próprias mulheres em participarem. Essa materialidade faz subentender, também, que as mulheres dispõem de mais tempo livre do que os homens. O serviço doméstico não é tido como uma ocupação. É o chamado "trabalho invisível".

Entrevistador - Aí, ele fala sempre pra você ir, é [nas atividades do movimento]?

Entrevistada D. - É, ele diz: "vá, eu não vou não!" Aí, eu digo, a pois eu vou! Aí, eu tava com vontade inté de mudar o cadrasto dele, eu fazer o meu cadrasto pra tirar o dele, mas só que não adianta, porque eu não tenho minha identidade... (...) Tudo é eu, tudo é eu, e ele nada! Aí, eu tava dizendo a ele: "assim, é mais melhor, quando eu tirar a minha identidade eu vou mandar..."

A entrevistada D. usa o termo "mandar", demonstrando a relação de hierarquia nas relações familiares. A autoridade é dada ao seu marido, pois é o nome deste que está no registro do lote (no MST, na maioria das vezes, o registro do lote está no nome das mulheres). Vê-se que a autoridade é dada em primeiro lugar ao homem, mas tal posição, embora naturalizada, é confirmada objetivamente pelo fato dos homens terem mais oportunidades sociais. Este fato é o fundamental na nossa sociedade, pois, se uma mulher está em uma condição social melhor, ela pode ter a autoridade perante os que estão em situação social pior. Porém, como demonstra os dados divulgados pelo Instituto de Pesquisa Econômica Aplicada (IPEA, 2012), os serviços domésticos continuam sendo uma atividade feminina, não importa a condição social.

Em apenas uma entrevista tivemos uma exceção ao que costuma ser relatado:

Entrevistador - E como os maridos veem as mulheres participando do movimento?

Entrevistada M. - Quando ele vê que eu num vou ele vai. Meu marido é assim.

Entrevistador - Ah, tá. Então melhor. 
Entrevistada M. - Quando eu num vou, num posso ir, ele vai no meu lugar.

A entrevistada usa, inclusive, o termo de que o marido a substitui quando ela não participa de alguma atividade, quando impera nas outras entrevistas o contrário. Porém, ela mesma admite a raridade desta relação com a expressão "meu marido é assim". O dela é assim, os outros, infelizmente, são diferentes.

A ideologia da mulher vista como propriedade é colocada no trecho a seguir:

Entrevistador - Mas não vai pra uma discoteca [nos momentos de descanso]... um barzinho, alguma coisa... [fala ao fundo um terceiro: "porque o marido não deixa"]

Entrevistada F. - Vou não. Nem ele deixa e nem ele gosta muito dessas coisas...

Não entra em questão se ela gostaria ou não fazer o que é sugerido pelo entrevistador. Nota-se, também, que o fato do próprio cônjuge não gostar "muito" de ir a bares é um adicional que melhora a situação de submissão da entrevistada, mas se ele não gosta, ela não vai, o comando continua sendo do homem.

A ideologia que reproduz a opressão de gênero dentro do capital é um exemplo do debate teórico sobre a discriminação feminina. A análise de nossas entrevistas, mesmo daquelas que participam do maior movimento social de trabalhadores, no Brasil, demonstram a reprodução da ideologia patriarcal, expressando mais claramente as contradições e sua consequente condicionante das relações e papeis sociais vigentes em que a mulher "cuida da casa" e os homens passam a se desenvolver mais, no que tange à sua experiência política no movimento. Como diz uma assentada:

Entrevistador - Quanto a essa participação das mulheres, você acha que os maridos acham bom, tentam colocar algum entrave, preferem que a mulher fique em casa?

Entrevistada - Nem todas. Tem deles que quando é pra uma mulher ir pra uma caminhada, eles acham ruim. Sabe que é tipo uma norma, só que eles ainda acham ruim, ficam assim, criticando... só que tem uns companheiros...

Entrevistador - Prefere que fiquem em casa... 


\section{Gênero, trabalho e ação política no setor agrícola alagoano.}

Entrevistada - É, mas só que é tipo assim, quando o marido não pode fazer uma coisa a mulher tem que fazer, sabe!? É por isso que é que nem diz aqui: somos um coletivo, o que o homem faz a mulher tem que fazer; não serviço pesado, digo assim uma caminhada, sabe? Agora, considerando, respeito!

As relações sociais marcadas pela sociabilidade do capital e potencializadas pela ideologia patriarcal ainda se fazem presentes dentro de diversos assentamentos, como demonstraram as falas das assentadas, pois mesmo chamando atenção para o caráter da coletivização das ações há uma separação das atividades entre homens e mulheres e quando essas participam das caminhadas têm que considerar o respeito.

Na seguinte fala "é por isso que é que nem diz aqui: somos um coletivo, o que o homem faz a mulher tem que fazer; não serviço pesado, digo assim uma caminhada, sabe? Agora, considerando, respeito!". O que é silenciado na expressão "Agora, considerando o respeito", é a vigilância que deve ser realizada, nas marchas, do comportamento adequado de homens e mulheres. A moral machista predomina sob o rótulo do respeito.

Em contrapartida, a fala da entrevistada põe em debate uma questão importante tratada anteriormente: a passagem do individuo ao "grupo". Pois quando se fala "somos um coletivo, o que o homem faz a mulher tem que fazer; não serviço pesado, digo assim uma caminhada, sabe?" traduz um sentimento de pessoas articuladas em um grupo que possui interesses específicos, como a luta pela terra, isso insere as lutas pontuais na ordem do dia.

Desse modo, embora tenha passado por diversas mudanças, a família nuclear ainda é uma instituição essencial para o funcionamento do modo de produção capitalista. Ela cumpre um papel econômico, ao responsabilizar o núcleo familiar pelos custos da manutenção da força de trabalho (presente e futura) e ideológico, pois as famílias são levadas a se ver como as únicas responsáveis pelo sucesso ou fracasso social de seus componentes, desconsiderando-se a influência econômica em suas vidas pelos cortes sociais, pela crise econômica etc. Além disso, aparentemente, a família oferece um refúgio necessário para aguentar a competitividade e a desumanidade do mundo "lá fora".

Certamente, não há nenhuma lei intrínseca ao capital que afirme que as opressões devam ser reproduzidas, mas é também um fato que, até agora, não houve momento sócio-histórico em que o capitalismo não se utilizou desse mecanismo para explorar mais. Como dito anteriormente, o próprio capital é feito de contradições. Se, em um momento, é concedido algum tipo de liberdade aos sujeitos, em outro, quando convir a este sistema, será retirada. 
A análise das materialidades para comparar os resultados teóricos conquistados pelo grupo mostraram a utilidade da naturalização do serviço doméstico como uma atividade feminina, seja para perpetuar as relações sociais úteis ao modo de produção capitalista, seja para dividir a classe trabalhadora. Mostrou-se também que a ideologia tem força material para interferir nas circunstâncias e que está intimamente relacionada às condições de produção.

\section{IDEOLOGIA PATRIARCAL E DISCRIMINAÇÃO FEMININA: AFETIVIDADE E SERVIDÃO DOMÉSTICA}

O recorte analítico neste momento parte da relação entre afetividade e servidão doméstica, que entendemos ser um mecanismo propulsor à manutenção da "servidão voluntária" (HIRATA, 2004). As mulheres entrevistadas relataram um cotidiano regulado pelo tempo da indústria da cana, através do trabalho de cuidado, o care (HIRATA, 2010), para a reprodução do trabalhador e do futuro trabalhador (MAGALHÃES, 2005). Como vemos a seguir:

Entrevistadora: Como é a rotina durante o corte da cana, que horas a senhora acorda, o que a senhora faz?

Entrevistada: Eu tô acostumada assim: acordar 4h, não gosto de ficar deitada até tarde. Hoje ainda fiquei porque ontem eu tava fazendo uma arrumação, ai a gente ainda vai terminar umas coisas na cozinha... mas eu tô acostumada a acordar cedo, é a "hora dos passarinhos". Dormir até tarde não dá pra mim não fazer comida cedo, e tem também os menino que estudam de manhã tenho $q$ ficar pra fazer café e tudo... eu que puxo ele da cama, porque se for por ele só ele não levanta não. É, eu levanto ele, eu mesma troco a roupa dele ele deitado, "boto" meia "boto" bota, eu comprei uma bandeja... Levo o café dele na cama... às vezes ele diz "vou tomar banho" ai eu digo: Então borá rápido, puxo ele pelas pernas e ele levanta e vai tomar banho, ai quando ele entra no banheiro, troca de roupa eu digo: "ói! falta pouco minuto", ai eu já tenho botado comida na bolsa... Ai fico na porta enquanto ele tá tomando café... quando eu vejo o ônibus passando ai eu digo: "O ônibus já vai passando lá em cima" ai ele vem sai e vai... tem vez que eu vou até o ponto com ele (Fonte: Trabalho na Agroindústria Canavieira de Alagoas Entrevista DM(I)M - 28, PIBIC-CNPq/ICS-UFAL, 20092010). 


\section{Gênero, trabalho e ação política no setor agrícola alagoano.}

O trabalho doméstico não remunerado envolve primordialmente o trabalho de cuidado direto (que diz respeito ao lidar imediato com o outro) e indireto (que se refere a tarefas ligadas ao cuidado do ambiente, por exemplo) -, sendo o trabalho de cuidado o que aparenta ser 'o maior componente das atividades domésticas não remuneradas' (IPEA, 2012), âmbito identificado como o lugar do feminino. A ordem capitalista torna o tempo social despendido pelas mulheres nas atividades domésticas, invisível. No Brasil, trata-se de um trabalho executado por $90 \%$ das mulheres abordadas em pesquisas recentes, estejam ou não inseridas no trabalho de mercado (IPEA, 2012; CEPIA; ONU MULHERES 2011; DIEESE, 2011). Assim, partimos do conceito de divisão sócio-sexual do trabalho (ANTUNES, 2007), por articular gênero e classe, aditando-o sentido encontrado na sociologia francesa, que conceitua essa divisão como um système (HIRATA, 2011, p. 40).

Questionamos o motivo de o capital não garantir a reprodução da força de trabalho, "tanto pela manutenção de um trabalho gratuito (por mais que mudanças tenham ocorrido) como pelo rebaixamento do salário feminino na produção direta" (MAGALHÃES, 2005, p. 36). Por que o trabalho doméstico é e continua a ser realizado no interior da família, gratuita e "voluntariamente" pelas mulheres? Parte da resposta a essa questão, como não poderia deixar de ser, remete-nos à lógica do capitalismo - que necessita da "servidão voluntária" para reproduzir a família, bem como, do patriarcado, que longe de ser superado, tem sido ressignificado na contemporaneidade.

Como nos aponta Hirata (2004), a questão também se encontra relacionada ao modo como a ideologia constrói os "modelos psico-afetivos da dominação", que foram pouco explorados pelos sociólogos. Isto quer dizer que, as noções de "servidão voluntária", de "consentimento" à dominação, assim como a convocação do "sentimento amoroso" são heurísticas para pensar o lugar dos afetos na reprodução da servidão doméstica. Tais relações precisam ganhar maior destaque tanto no âmbito acadêmico, investigativo, quanto nos espaços da vida pública, enquanto problema social e político. Parte, também, de uma problemática de classe que combina e ultrapassa os gêneros em si, revelando uma lógica societal.

Disso, o trabalho doméstico não remunerado implica a dimensão do afeto devido ao grau de interpessoalidade,

[...] realizar trabalho gratuito (de modalidades bastante diversas, como o trabalho doméstico repetitivo, o cuidado com as crianças [care], a gestão familiar da sociabilidade etc.) por afeto contribui a perpetuar a dominação masculina [...] (HIRATA, 2004, p. 03).

Esse trabalho não é coberto pelo salário (IASI, 2011, p. 139). O problema é "resolvido" pelo patriarcado, de modo que a mercadoria força de trabalho tem 
parte da composição de seu valor na atividade de reposição de sua energia. Tratase, pois, de discutir mais profundamente como se configura a divisão sócio-sexual do trabalho no capitalismo, qual o papel do trabalho doméstico não remunerado e como se localiza diante das relações de produção de mercadorias. Há conjugação? Em caso de resposta positiva, que qualidade comporta?

Economistas da Universidade de Paris, Rizavi e Sofer (2008) apresentaram dados coletados em 10 países da União Européia sobre trabalho doméstico e a organização do tempo dos casais (levantamentos realizados em 2004) e inferiram a seguinte regularidade: as mulheres se encarregam de uma proporção que varia entre $60 \%$ e dois terços do trabalho doméstico. A Suécia e alguns dos países nórdicos encontram-se entre os mais igualitários na divisão do tempo doméstico dos casais. Entre os menos igualitários, destacam-se os países recém incorporados à União Europeia, e a França, país por eles elencado para ser comparado ao país economicamente mais rico da América, os Estados Unidos, e visualizar algumas dimensões da relação entre status econômico da nação e desigualdade de gênero no compartilhamento do tempo doméstico.

Os resultados apontam que os estadunidenses gastam cerca de três quartos de hora diárias a menos em trabalho doméstico, 2h59min contra as $3 \mathrm{~h} 43 \mathrm{~min}$ diários da população francesa, aproximando-os dos suecos e dos nórdicos. Nessa comparação, a França mantém-se ainda como país menos igualitário na divisão por gênero do tempo doméstico, tomando $65 \%$ do tempo feminino, enquanto o país americano libera $2 \%$ desse tempo (RIZAVI; SOFER, 2008).

[...] pode-se atribuir esse excedente de trabalho doméstico ao mesmo tempo a um equipamento em bens duráveis mais limitado (lava louça, micro-ondas etc.) e a substitutos mercantis (congelados, pratos prontos etc.) menos acessíveis (mais raros e/ou relativamente mais caros) [...] (RIZAVI; SOFER, 2008, p. 116).

Contudo, a possibilidade de partilha mais equilibrada do tempo doméstico não diz respeito necessariamente a uma divisão do tempo dos afazeres, e isso independe da aparelhagem doméstica e dos serviços externos, públicos ou privados, que possam ser acessados pelas famílias. Tais acessos são importantes para permitir às mulheres terem cada vez mais seu tempo liberado do mundo doméstico e estarem disponíveis para a vida pública.

A especialização por gênero permanece em questões sumamente importantes no que tange ao enraizamento de uma divisão sócio-sexual do trabalho sempre ligada aos fundamentos da cultura patriarcal: "[...] das mulheres no que diz respeito à roupa e à cozinha, e dos homens nos consertos, na reparação ou na manutenção do carro, por exemplo. Apenas algumas tarefas, como as 


\section{Gênero, trabalho e ação política no setor agrícola alagoano.}

compras ou a jardinagem, ou, em menor medida, a cozinha, são partilhadas de maneira mais igualitária" (RIZAVI; SOFER, 2008, p. 116).

Em maio de 2012, o IPEA publicou um comunicado intitulado Trabalho para $o$ mercado e trabalho para a casa: persistentes desigualdades de gênero, afirmando que,

Em 2009, 90\% das mulheres brasileiras com 16 anos ou mais de idade afirmaram realizar afazeres domésticos, comparados a 50\% dos homens. Desde 1995, podem ser percebidas suaves oscilações tanto entre os homens como entre as mulheres. Há uma tendência de estabilidade na proporção de pessoas que realizam afazeres domésticos, sendo que as mulheres mantêm-se em torno dos $90 \%$ e os homens oscilam entre 46 e $50 \%$. Os diferenciais de raça e de região também não são representativos, com a exceção do percentual de homens da Região Sul que afirma realizar afazeres domésticos: chega a $61 \%$, valor consideravelmente superior à média nacional encontrada para os homens (50\%).

Em documento lançado em 2011 pela ONU Mulheres e pela Cidadania, estudo, pesquisa, informação e ação (CEPIA), O Progresso das Mulheres no Brasil 2003-2010, organizado por Bruschini et al., afirmam que os dados mais recentes "evidenciam uma nova identidade feminina, voltada tanto para o trabalho quanto para a família", por consequência, "do ponto de vista das políticas públicas, um dos maiores desafios dos novos tempos no Brasil é promover a articulação entre família e trabalho".

A primeira contradição perdura: "se o dia tem 24 horas para todas as pessoas, torna-se muito difícil para as mulheres ampliarem a contento sua jornada de trabalho remunerada se continuarem se dedicando ao trabalho não remunerado como hoje o fazem" (2011, p. 13.).

Considerando tempo enquanto categoria sociológica, a conceituação perpassa a noção de que a temporalidade tem uma variação histórico-cultural, múltipla, e mesmo no interior de cada cultura devemos falar em tempos, no plural.

A centralidade do tempo de trabalho na era moderna dominada pelo ethos capitalista não pode excluir as outras experiências de tempo existentes (CARDOSO, 2007). Buscamos conceber o tempo a partir, portanto, de sua construção social, compreendendo-o, como discute Ana Cardoso (2007), primeiramente como uma experiência subjetiva que, portanto, não pode ser considerada de modo linear, e sim, a partir de sua trajetória histórica: há tempo de trabalho e tempo de não trabalho; a redução do tempo de trabalho ao trabalho gerador de valor do ponto de vista do capitalismo exclui não apenas os tempos 
vividos em experiências externas ao espaço da produção, mas transforma inclusive a própria representação do trabalho; de modo que o trabalho no espaço da reprodução social não é considerado como tal, marcado simbolicamente com menor valoração social.

Elias (1998, p. 15-17), discutindo a relação entre ser social e tempo, destaca:

Deparamos aqui com o problema específico da relação entre o tempo e os relógios. [...] A disposição dos ponteiros tem por função indicar aos seres humanos a posição que eles e outros ocupam atualmente no vasto fluxo do devir, ou então, de quanto tempo precisaram para ir de um lugar a outro. (...) O tempo tornou-se, portanto, a representação simbólica de uma vasta rede de relações que reúne diversas sequências de caráter individual, social e puramente físico.

Nesse sentido, o relógio é uma expressão de necessidades históricas dispostas por determinados tipos de organização social a partir da modernidade, como substituto dos meios naturais de percepção do tempo. Não obstante, fica a pergunta: o que os relógios medem? Diríamos: não é o tempo, mas os usos sociais do tempo.

O tempo despendido como trabalho não remunerado não se define somente por arranjos privados baseados em convenções tradicionais de gênero, mas também pela disponibilidade de serviços públicos e pela configuração das políticas sociais, que, historicamente, desde seu desenho contam com o trabalho feminino não remunerado. São exemplos os horários de funcionamento e a ausência de refeições nas escolas, a ausência de transporte escolar público universal, os limites da política de assistência à saúde e a precariedade da assistência a pessoas idosas e a pessoas com deficiência (IPEA, 2012, p. 16).

Sorj e Fontes (2012) afirmam que, provavelmente, o principal desafio a ser superado pelas políticas públicas no Brasil é o de "conciliar o combate à pobreza com a promoção da autonomia das mulheres", desafio articulado ao da necessidade de "mudança na distribuição das responsabilidades domésticas entre homens e mulheres" (2010, p. 73). 
Gênero, trabalho e ação política no setor agrícola alagoano.

A perda de poder político é uma consequência imediata, o tempo "naturalmente" dedicado ao lar e aos filhos é obstáculo central ao questionamento da suposta inferioridade feminina, posto que a identificação da desigualdade e, principalmente, a possibilidade de busca por igualdade exige a ocupação dos espaços da rua, nos quais se localizam as fontes de poder e de disputa.

A relação imediata que temos é entre jornada de trabalho na produção e tempo socialmente gasto para a garantia da reprodução social. De acordo com Dedecca (2004, p. 25), “a regulação da jornada de trabalho até os anos 1970, visava a separação entre o tempo para a reprodução econômica e aquele para reprodução social", objetivando limitar a extensão do tempo econômico sobre o tempo total das pessoas e famílias. O autor defende, desse modo, que o tempo do trabalho doméstico seja conceituado como "tempo para a reprodução social", dimensão fundamental para a resolução de problemas da acumulação capitalista.

Para a manutenção diária da força de trabalho, é necessário um tempo externo àquele despendido no espaço da produção (mínimo para a garantia do trabalhador vivo [salário], ultrapassado pela produção para formar mais valor [excesso quantitativo de trabalho], que garante a forma capitalista de produção de mercadorias). O contrato por tempo, cronometrado de forma extenuante para garantir o "processo de valorização", não permite que as atividades necessárias à manutenção do trabalhador sejam garantidas (MARX, 1985) pelo próprio sujeito, tampouco é possível observar a coletivização de tais atividades.

Inquestionável que o debate sobre o uso do tempo no capitalismo do século XX não mais permite identificar o tempo não criador de valores de troca como tempo doméstico. O papel cumprido na reprodução social, no âmbito das famílias e domicílios articula-se ao tempo econômico para a acumulação capitalista. Um não se processa sem o outro, causando sistematicamente pressão sobre o tempo livre da população (DEDECCA, 2004, p. 25).

Os estudos sobre o trabalho doméstico não remunerado a partir da perspectiva marxista necessitam se aprofundar tanto do ponto de vista teórico como das práticas dos movimentos dos trabalhadores. Sem a reprodução social não há produção.

\section{CONCLUSÃO ${ }^{5}$}

${ }^{5}$ Agradecemos a todas as trabalhadoras que possibilitaram a efetivação das pesquisas aqui apresentadas, em especial, ao Movimento dos Trabalhadores Rurais Sem Terra (MST), que 
Diante do que foi exposto acima, nossa pesquisa conclui que, embora a família dentro do sistema capitalista funcione como uma célula econômica fundamental para garantir a acumulação de riquezas e o direito de herança, o trabalho doméstico realizado nos interiores do lar familiar não é parte fundante do sócio-metabolismo do capital.

A opressão, não só de gênero como as demais opressões, mas aqui neste espaço foi especificamente a do gênero feminino, de fato foi e é, até os dias atuais, utilizada pelo capital como forma de superexploração do trabalho. No entanto, prescindir desse método de superexploração é uma possibilidade possível, ainda dentro do capital.

Na essência e na lógica do capital pouco importa a cor e o gênero da força de trabalho, importa-lhe apenas a capacidade de extração e potencialização de sua força produtiva. Sabemos, entretanto, que o capitalismo proporciona determinados tipos de liberdades que nunca alcançam as últimas consequências e uma delas é a liberdade da mulher. Nesse sentido, suas contradições criam ferramentas para que se impulsionem transformações ainda mais objetivas, e para isso, o entendimento do homem em seu fazer históricoé fundamental.

Para o capitalismo, a realização do trabalho doméstico no âmbito privado é extremamente importante. $\mathrm{O}$ papel cumprido pela mulher na realização do trabalho doméstico no âmbito privado garante a produção, reprodução, renovação ou recuperação do trabalhador. A exaustão do trabalhador pela exploração cotidiana de seu trabalho é remediada pela realização do trabalho doméstico, a custo zero para o capital. E ainda que possível dentro do capital o abandono desse método de exploração, não se dará sem um acirramento das contradições sociais. Fica impelida, assim, à humanidade uma difícil tarefa de emancipação.

"A servidão doméstica parece assim refratária às grandes mutações da atividade feminina", afirma Hirata (2004), discutindo que a estrutura do trabalho doméstico remete a uma relação social de serviço, e que as modalidades de sua realização variam segundo as classes sociais e segundo as possibilidades econômicas da família e aos caracteres societais (cultural, político-econômico etc.). O capital segue exercendo autoridade patriarcal sobre a mulher, de modo que a reprodução da força de trabalho é garantida, sem custos adicionais: enquanto assalariada a mulher tem sua atividade modificada pelas eventualidades do casamento, da maternidade e da posterior criação dos filhos, sendo impedida de

de braços abertos nos receberam e partilharam conosco seu espaço de resistência e luta cotidiana. Esperamos que as discussões aqui realizadas possam contribuir com a fundamental provocação do debate acerca da emancipação feminina e seu lugar central na luta do conjunto da classe trabalhadora em busca da emancipação humana. 
Gênero, trabalho e ação política no setor agrícola alagoano.

abandonar as tarefas domésticas, servindo, também, como suporte para o trabalho masculino.

\section{REFERÊNCIAS CITADAS}

ANTUNES, Ricardo. A desconstrução do trabalho e a perda dos direitos sociais. Evocati Revista, n. 19, jul./2007. Disponível em:

$<$ http://www.evocati.com.br/evocati/artigos.wsp?tmp_codartigo=134>. Acesso em: BRUSCHINI, Cristina et al. Trabalho, renda e políticas sociais: avanços e desafios. In: BARSTED, Leila Linhares; PITANGUY, Jacqueline (Orgs.). O progresso das mulheres no Brasil 2003-2010. Rio de Janeiro: CEPIA, 2011.

CARDOSO, Ana. Tempos de trabalho, tempos de não trabalho: vivências cotidianas de trabalhadores. Tese (Doutorado em Sociologia)- Universidade São Paulo, São Paulo, 2007.

CEPIA; ONU Mulheres. O progresso das mulheres no Brasil 20032010. BARSTED, Leila Linhares; PITANGUY, Jacqueline (Orgs.). O progresso das mulheres no Brasil 2003-2010. Rio de Janeiro: CEPIA; Brasília: ONU Mulheres, 2011. DEDECCA, Cláudio Salvadori. Tempo, Trabalho e Gênero. In: COSTA, Ana A.; OLIVEIRA, Eleonora M. de; LIMA, M. E. B. de; SOARES, Vera (Orgs.).

Reconfiguração das relações de gênero no trabalho. São Paulo: CUT Brasil, 2004. ELIAS, Norbert. Sobre o tempo. Rio de Janeiro: Jorge Zahar, 1998 GONÇALVES, Renata. O feminismo marxista de Heleieth Saffioti. Lutas Sociais, São Paulo, n. 27, p.119-131, 2º sem. 2011.

HIRATA, Helena. Genre, travail et care: l'état des travaux en France . Revista Latino-americana de Estudos do Trabalho, ano 16, n. 26, p. 37-56, 2011. HIRATA, Helena. Teorias e práticas do care: Estado sucinto da arte, dados de pesquisa e pontos em debate. In: FARIA, N.; MORENO, R. (Org.). Cuidado, Trabalho e Autonomia das Mulheres. São Paulo: SOF, 2010. Trabalho doméstico: uma servidão "voluntária"? In: Coleção Cadernos da Coordenadoria Especial da Mulher. 2004. Nova Divisão Sexual do Trabalho? São Paulo: Boitempo, 2002.

IASI, Mauro Luis. Ensaios sobre consciência e emancipação. São Paulo: Expressão Popular, 2011.

IPEA. Trabalho para o mercado e trabalho para a casa: persistentes desigualdades de gênero. Comunicados IPEA, n. 149. Brasília: IPEA, 2012.

MAGALHÃES, Belmira. Trabalho, Gênero e Educação. In: MAGALHÃES, Belmira; BERTOLDO, Edna (Org.). Trabalho, Educação e Formação Humana. Maceió:

Edufal, 2005. 
. Uma análise da representação de gênero na literatura brasileira contemporânea. In: Revista EXU, n. 35, Fundação Casa Jorge Amado, Salvador, abr./jun., 1997, p. 28-33.

MARX, Karl. O 18 Brumário de Luis Bonaparte. In: A revolução antes da revolução. São Paulo: Expressão Popular, 2008.

1985. O Capital - Crítica da Economia Política, v. 1. São Paulo: Nova Cultural,

MÉSZÁROS, István. Filosofia, ideologia e ciência social. São Paulo: Boitempo, 2008.

ORR, Judith. Marxismo e feminismo hoje. Lutas Sociais, São Paulo, n. 27, p.132143, $2^{\circ}$ sem. 2011.

RIZAVI, Sayyid S.; SOFER, Catherine. Trabalho doméstico e organização do tempo dos casais: uma comparação internacional. In: OLIVEIRA COSTA, Albertina de et al. Mercado de trabalho e gênero: comparações internacionais. Rio de Janeiro: Editora FGV, 2008.

SORJ, Bila; FONTES, Adriana. Políticas públicas e a articulação entre trabalho e família. In: FARIA, Nalu; MORENO, Renata (Orgs.). Cuidado, trabalho e autonomia das mulheres. São Paulo: SOF, 2010.

\section{REFERÊNCIAS CONSULTADAS}

ABRAMO, Laís. A situação da mulher latino-americana - o mercado de trabalho no contexto da reestruturação. In: CAPELLIN, Paola; DELGADO, Didice G.; SOARES, Vera (Orgs.). Mulher e Trabalho - experiências de ação afirmativa. São Paulo: Boitempo, 2000.

ANDRADE, Manuel Correia de. Usinas e destilarias das Alagoas: uma contribuição ao estudo da produção do espaço. Maceió: EDUFAL, 1997.

ANTUNES, Ricardo. Adeus ao trabalho? 5. ed. São Paulo: Cortez; Campinas, SP: Editora da UNICAMP, 1998.

ARUZZA, Cinzia. Rumo a uma "União queer" de marxismo e feminismo? Lutas Sociais, São Paulo, n. 27, p. 159-171, 2o sem. 2011.

BORÓN, A. A. El marxismo y la filosofia política. Crítica Marxista, São Paulo, n. 13, p. 69-94, 2001.

BOURDIEU, Pierre. Contrafogos 2: por um movimento social europeu. Rio de Janeiro: Jorge Zahar, 2001.

BRUSCHINI, Cristina; LOMBARDI, Maria Rosa. Mulheres e homens no mercado de trabalho brasileiro: um retrato dos anos 1990. In: MARUANI, Margaret; HIRATA, Helena (Orgs.). As novas fronteiras da desigualdade: homens e mulheres no mercado de trabalho. São Paulo: Editora Senac, 2003.

D'ATRI, Andrea. Feminismo e marxismo: 40 anos de controvérsias. Lutas Sociais, São Paulo, n. 27, p. 144-158, 2º sem. 2011. 
Gênero, trabalho e ação política no setor agrícola alagoano.

FREDERICO, Celso. Emancipação política e emancipação humana. In:

FREDERICO, C. O jovem Marx 1843-44: as origens da ontologia do ser social. São

Paulo: Cortez, 1995, p. 93-122.

ENGELS, Friedrich. A origem da família, da propriedade privada e do Estado. Rio de Janeiro: Civilização Brasileira, 1975.

FLORÊNCIO, Ana M. G. et alii. O. Análise do discurso: fundamentos \& práticas.

Maceió: EDUFAL, 2009.

HEREDIA, Beatriz Alasia de. Formas de dominação e espaço social - a

modernização da agroindústria canavieira em Alagoas. São Paulo: Marco Zero;

Brasília, DF: MCT/CNPq, 1988.

LOVATTO, Angélica. Desvendando "O Poder do Macho": um encontro com Heleieth Saffioti. Lutas Sociais, São Paulo, n. 27, p.110-118, 2º sem. 2011.

LUKÁCS, G. As Bases Ontológicas do Pensamento e da Atividade do Homem. In: COUTINHO, Carlos N.; NETTO, José P. (Orgs.). O jovem Marx e outros escritos de filosofia - György Lukács. Rio de Janeiro: Editora UFRJ, 2007.

LUKÁCS, G. O Trabalho. Tradução de Ivo Tonet. Maceió, 1997, mimeo.

MAGALHÃES, Belmira. As Marcas do corpo contando a História. Maceió: Edufal, 2005.

MAGALHÃES, Belmira et al. Gravidez, saúde e Estado. Curitiba: Hd Livros, 1998.

MAGALHÃES, Belmira; SILVA, Geice. A mulher no trabalho, na família e na universidade. Revista Eletrônica Arma da Crítica, ano 2, n. 2, mar./2010.

. Trabalho, Capitalismo, Gênero: entender o imbricamento para agir. Anais

do VII Seminário de Trabalho, UNESP, Marília, 2010.

MARX, Karl. Manuscritos econômicos filosóficos. São Paulo: Boitempo, 2004.

MARX, Karl; ENGELS, Friedrich. A Ideologia Alemã. São Paulo: HUCITEC, 1993.

MASCARENHAS, Angela C. B. Objetividade e subjetividade do trabalho. In: O trabalho e a identidade política da classe trabalhadora. Goiânia:

Alternativa, 2002, p. 49-81.

MESZÁROS, István. A ordem da reprodução sociometabólica do capital. In: Para além do Capital - rumo a uma teoria da transição. São Paulo:

Boitempo, 2002.

. A ativação dos limites absolutos do capital. In: . Para além do

Capital - rumo a uma teoria da transição. São Paulo: Boitempo, 2002.

NETTO, José Paulo (Org.). Lukács. São Paulo: Ática, 1981. [Coleção Grandes

Cientistas Sociais]

NETTO, José Paulo; BRAZ, Marcelo. Economia Política - uma introdução crítica.

São Paulo: Cortez, 2007.

NOGUEIRA, Claudia M. O trabalho duplicado: a divisão sexual no trabalho e na reprodução (um estudo das trabalhadoras do telemarketing). São Paulo: Expressão Popular, 2004. 
RICHARD, Anne-Marie Daune. Qualificações e representações sociais. In: MARUANI, Margaret; HIRATA, Helena (Org.). As novas fronteiras da desigualdade: homens e mulheres no mercado de trabalho. São Paulo: Editora Senac, 2003.

SAUER, Sérgio. Terra e Modernidade: a reinvenção do campo brasileiro. São Paulo: Expressão Popular, 2010.

SILVA, Maria Aparecida de Moraes. Errantes do fim do século. São Paulo: Editora da UNESP, 1999.

SAFFIOTI, Heleieth I. B. A questão da mulher na perspectiva socialista. Lutas Sociais, São Paulo, n. 27, p. 82-100, 2º sem. 2011.

SAFFIOTI, Heleieth I. B. O poder do macho. São Paulo: Moderna, 1987.

TERTULIAN, Nicolas. Metamorfoses da filosofia marxista: a propósito de um texto inédito de Lukács. Crítica Marxista, São Paulo, n. 13, p. 29-44, 2001.

TOLEDO, Cecília. Mulheres: o gênero nos une, a classe nos divide. São Paulo: Sundermann, 2008.

WOOD, Ellen. Democracia contra capitalismo: a renovação do materialismo histórico. São Paulo: Boitempo, 2003.

XINRAN, Xue. As boas mulheres da China: vozes ocultas. São Paulo: Companhia das Letras, 2003. 